\title{
Improving the quality of construction project execution at University of Hail
}

\author{
Isam A. Q. A. R. El Badawi 1, *, Mohammed Al-Nais ${ }^{2}$, Mohamed ELashmawy ${ }^{2,3}$ \\ 1Industrial Engineering Department, University of Hail, Hail, Saudi Arabia \\ ${ }_{2}^{2}$ Mechanical Engineering Department, University of Hail, Hail, Saudi Arabia \\ ${ }^{3}$ Engineering Science Department, Faculty of Petroleum and Mining Engineering, Suez University, Suez, Egypt
}

\section{ARTICLE INFO}

\section{Article history:}

Received 21 March 2017

Received in revised form

17 May 2017

Accepted 14 June 2017

\section{Keywords:}

Construction

Training

Learning competencies

\begin{abstract}
A B S T R A C T
The research reported in this study is part of a series of programs on quality in the College of Engineering at the University of Hail ( $\mathrm{UoH})$, and funded by the Deanship of Academic Research by a grant for project number (E-27-ME). The programs aim at enhancing the performance level of the current construction projects in the new campus. The project is funded by the deanship of academic research at $\mathrm{UoH}$. The construction projects in the UoH have developed very rapidly, The latest statistics show that approximately $50 \%$ of UoH construction has been delayed in the last five years. As a result, the construction projects in $\mathrm{UoH}$ are facing a huge deadlines delay, a compromise in quality, and long waiting times to operate the project for academic services. There are several causes for the delay, which are combined into three areas, namely late executive decisions, communication among teams, and unplanned project expansion. The study surveyed the opinion of 169 engineers involved in the projects at $\mathrm{UoH}$ and determined the content of the engineering training courses necessary to ensure the improvement of the quality in the execution of construction projects. A survey was distributed among different levels of engineers and a list of courses is suggested to show the survey results.
\end{abstract}

(C) 2017 The Authors. Published by IASE. This is an open access article under the CC BY-NC-ND license (http://creativecommons.org/licenses/by-nc-nd/4.0/).

\section{Introduction}

The ultimate purpose of any industry is to meet the demand of the customer on time with zero defects and at the lowest cost. In the construction industry, the completion of the construction project on time with minimum waste could be described as the ultimate goal. Adherence to standards and abidance to the critical path of the project execution are determinants of effectiveness, and it is often the responsibility of quality engineers to ensure such adherence and abidance. Construction projects may gain advantage over their competitors by improving upon productivity to build projects at lower costs. Construction project operations take place onsite and this workplace is where construction activities progress may be improved. Improvement in construction is not possible without identifying factors that influence the construction productivity. Previous studies on productivity indicate that a

\footnotetext{
* Corresponding Author.

Email Address: isam149@gmail.com (I. A. Q. A. R. El Badawi) https://doi.org/10.21833/ijaas.2017.07.024

2313-626X/C) 2017 The Authors. Published by IASE.

This is an open access article under the CC BY-NC-ND license

(http://creativecommons.org/licenses/by-nc-nd/4.0/)
}

broad range of factors could affect productivity. These factors may be classified into three categories: industry-related, labor-related, and managementrelated (Adrian, 1987). The industry-related productivity factors include governmental interference, regulation burdens, local unions, and politics. Some of the labor-related factors include motivation, experience, skill, and training, while the management-related factors include planning and direction of the project (Mojahed and Aghazadeh, 2008). Establishing a rigorous quality standard for a project completion and delivery has a significant impact on the overall construction process and consequently results in significant cost and time savings. Since quality standards pertaining to accurate measurements and effective strategies to enhance construction productivity were inadequate in the construction projects at the $\mathrm{UoH}$, these projects suffered from problems of delay and unnecessary waste. The high interest in an expedited completion of the construction project at the UoH resulted in the disruption of many projects as well as uncontrollable construction process. This study proposes that improving the quality of the construction project execution could be achieved through rigorous and well-designed engineering 
training programs. Such an undertaking will require engineering manpower in the field to be equipped with the skills suggested competencies developed by the research team of this study. In this study, trained engineers are defined as engineers who are competent by virtue of their fundamental engineering training to apply the scientific methods and envisage to the analysis and solution of engineering problems.

\subsection{Engineering training in KSA: A brief overview}

A quick survey of the engineering training programs in the KSA shows a growing investment and interest in this important field. In 1975 two engineering officers from the General Directorate of Military Works (GDMW), Ministry of Defense and Aviation (MODA) were flown to USA to attend an engineering training program organized by US (AlYousefi et al., 1999). In 1982, 150 Saudi engineers and professionals have attended the first engineering training seminar in Riyadh, Saudi Arabia with assistance from a well-known value UK engineering consulting firm. In 1988, King Saud University (KSU) developed a standalone postgraduate course for engineering training named "Value Engineering" under the umbrella of the Construction Engineering Management program. Shortly after that in the same year KSU initiated a community collaboration program to provide engineering training consultation for academic facilities, educational infrastructure, and governmental projects. In 1989, The Saudi Society of Engineers (SSE) developed the first engineering training program in coordination with the General Directorate of Military Works. Recently, a growing number of public parties have shown great interest in engineering training. For example:

\subsubsection{The Saudi council of engineers}

The Saudi Council of Engineers (SCE) is a scientific professional body under the supervision of the Ministry of Commerce with many established branches within the KSA (SCE, 2012), and is expressed in this material Authority system. The Commission Council aims to promote the engineering profession, facilitate engineers and engineering establishments to reach ideal solutions, enhance the level of performance, and encourage innovation and creativity to achieve an internationally recognized position in order to improve the level of the profession and employees. Al-Hammad and Assaf, 1996) summarized the objectives of the SCE as follows:

- Lay the foundations and standards of practice and development, including the license conditions.

- Develop rules and the necessary examinations to obtain professional degrees.

- To prepare studies, research and statistics on the people and the branches of engineering,
- Disseminate and issue professional and scientific journals

- Organize courses and conferences, seminars and exhibitions related to the profession,

- Provide technical advice in the field of competence and in accordance with the regulations approved by the Board of Directors.

\subsection{The institute of public administration (IPA)}

The Institute of Public Administration was founded in 1961, as a body-corporate, autonomous government agency. The purpose of the Institute was to increase the efficiency of public employees and to educate them so as to make them capable of shouldering their responsibilities and use their jurisdiction in a manner that would raise the level of administration and support the foundation of national economic development. In addition, the IPA contributes to the administrative organization of government departments, offers consultations on administrative problems referred to it by government ministries and agencies, undertakes administrative research works, and enhances cultural ties in the field of public administration (IPA, 2012).

\subsubsection{IPA engineering training programs}

IPA engineering training programs are targeted programs to develop the skills of engineers in the local and international agencies. They conduct training sessions which boost the engineers' productivity, and provide them with the knowledge, skills and attitudes that lead to positive development of the project work. The Institute designs and implements these programs according to the needs of engineering projects. IPA engineering training programs focus on skills and abilities that are essential for engineering projects quality and progress enhancement. To implement this project, IAP formed the Institute committees to fragment programs into sectors of training, where it breaks each program to specific technical engineering skills such as being able to increase the effectiveness of trainee's performance capability in the field (IPA, 2012)

\subsubsection{IPA major training activities}

1. Set up and implement in-service training programs for various employment grades in the government.

2. Set up pre-service programs in various administrative fields according to market needs.

3. Conduct workshops and seminars for the executive branch in the government.

4. Sponsor conferences and symposia concerned with administrative development issues.

5. Provide consultations to government agencies and assist in their implementation. 
6. Encourage the authoring and publishing of original works and conducting research and administrative studies related to administrative development.

7. Translate into Arabic outstanding international works in the fields relevant to the IPA's line of work.

8. Classify government documents and facilitate their access.

9. Seek membership with regional, Arab and international institutions and organizations in the field of administrative development.

\section{Methodology}

The research methodology in this study includes semi-formal interviews at the construction project site at the $\mathrm{UoH}$ as well as a written questionnaire submitted to the engineering head office at $\mathrm{UoH}$ campus. After several visits to the sites, a number of are specific engineers accepted to participate in the questionnaire and the interview

\subsection{Semi-formal interviews}

The semi-interviews were held in two different locations: At the engineering consultant office and at the construction site in the period prior to conducting these interviews, the researchers had the chance to meet with a number of senior engineering staff and to obtain valuable information on the topic of the study. Then, the researchers conducted a group discussion with the field engineers who were enthusiastic to share their concerns and their perceptions in identifying some of the training competencies for quality engineering training. The semi-formal interviews were primarily conducted to:

- furnish the floor for communication between the research group and the engineering crew at the UoH construction site;

- assess the level of urgency for engineering training;

- investigate about the required engineering training competencies;

- assess the relevance, appropriateness and importance of the questions included in the questionnaires;

- to comment on the proposed preliminary list of training titles to be conducted

- understand the challenges facing the engineering project from the perspective of the engineering staff

- to explore the specific engineering training needs

- form an idea about the anticipated challenges.

\subsection{Questionnaire design}

Questionnaires have been carried to the engineering consultant office, as the latest to return it back to the researcher after responding to the questionnaire forms. The responses were adequate but slow, which forced the researchers to visit each engineering project to encourage an expedited completion of the questionnaire.

The purpose of the questionnaire is to identify, categorize, and prioritize the current engineering training competencies for the construction engineering projects at $\mathrm{UoH}$. The study aims to generate a targeted analysis and assessment of the current engineering training needs. Also, the study is proposes to generate responses and achieve consensus from a selected sample of multi engineering disciplines. The anticipated findings are expected to contribute to establish a guideline for training skills and knowledge needed to improve the quality of the current and future projects at $\mathrm{UoH}$. The questionnaire is divided into the following five sections:

1. Information on the participant's background and interest

2. Rating the importance of specific skills to be included in the training program

3. Statements approval and denial.

4. Agreement level

5. Comments

To achieve this, 123 questionnaires were distributed to selected engineers who are involved in the construction engineering projects at the UoH.

\subsection{Research method limitation}

The following limitations were inherent to the study:

- The participants' input and feedback were not uniform in value and depth. The difference was caused by the participants' background and seniority level.

- In spite of the explicit wording of the goals and objectives of the study, a few participants occasionally diverted from the study's objectives, and were occasionally off tune with some of their responses.

- The participants' personal and professional responsibilities limited the amount of time and effort they could invest in responding to questionnaires.

- The study was limited to the University of Hail engineering projects.

- The study was delimited to the number of responses and feedback received within the timeline of questionnaire plan.

\section{Results}

A summary of the majors of the participating engineers and their years of experience in the field is shown in Fig. 1. The second section of the questionnaire asked the participants to rate the potential skills to be included in the training program according to their influence on the performance and progress of the engineering projects at the UoH. To achieve this, 123 
questionnaires were distributed to selected engineers who play a major role in the engineering training project. The purpose of the questionnaire was to collect data to identify the decision factors and to determine their overall importance in the decision making process.

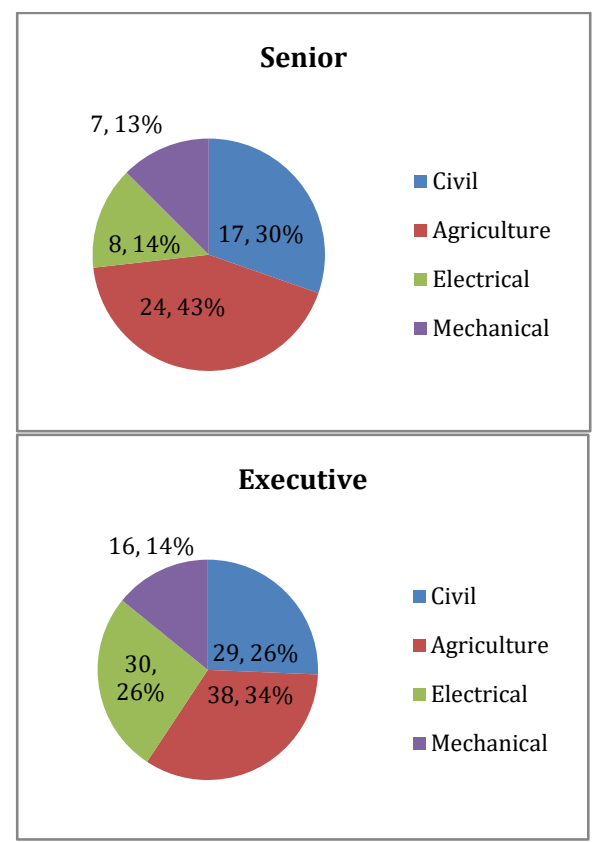

Fig. 1: Participants engineering counts and backgrounds majors and experience

\subsection{Questionnaire finding and results}

The demography of the respondents shows that most of them were executive civil engineers with less than 10 years of experience; while the lowest respondents were senior architectural engineers Fig. 2. The collected data from the respondents shows a high importance of including the problem solving skills and the ability of material handling in the engineering training program Fig. 3. On the other hand, some of the skills rated as a moderate importance such as ability transform obstacles into opportunities. One of the reasons stated from the engineering consultant office was because of the lack of understanding the terminology since the English language is the second language in the KSA. Moreover, most of the mechanical engineers rated HVAC processing principles and techniques as very important skills to include in the engineering training programs Fig. 4.

It was strongly evident that there is a tangible shortage in managerial and quality control skills among the executive engineers, which most likely generated from a low level of orientation and continuous improvement plans from the office of engineering projects in UoH. Finally, the Yes/No questions:

- Emphasized the significance of including specific skills and abilities in some suggested courses with time interval future engineering training program for UoH projects.
- Supported the validity of the assumption that engineering training will enhance the quality of engineering performance in UoH projects.

- Developed a basic criteria for the engineering training needs

- Estimate the time interval of suggested topic in the training program

The following diagrams show questionnaire responses distribution.

Section 1: Respondents Engineering Background?

Section 2: Importance of including engineering skills and abilities in the training (Table 1): Rate the importance of including the following skills in the quality engineering training program. Rate the importance of including the following abilities in the quality engineering training program (Table 2).

Section 3: Confirmation or denying statements is shown in Table 3, Fig. 5 and 6.

Section 4: Agreement/Disagreement statements are shown in Table 4 and Fig. 7.

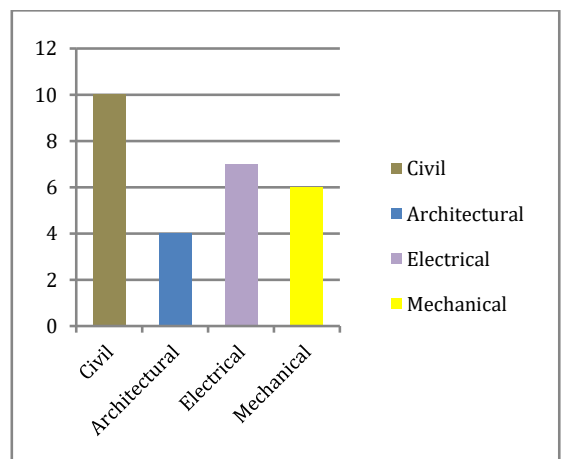

Fig. 2: Respondents engineering background

Table 1: Importance of skills in the quality engineering training program

Q1 Project materials safety

Q2 Failure troubleshooting and system analysis

Q3 Engineering Metrology equipments hands-on applications installation

Q4 Engineering Metrology equipment alignment and

Q4 calibration

Q5 Techniques of preparing and modifying contracts

Q6 Problem-solving skill

Q7 Soil sample preparations

Q8 Electronic equipment instrumentation

Q9 Materials handling and installations

Q10 Engineering measurement

Q11 Tactics of concrete processing

Q12 HVAC processing principles and techniques

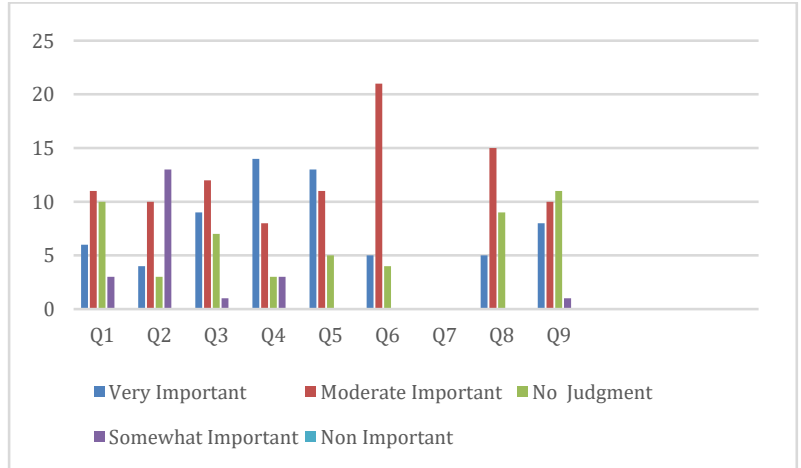

Fig. 3: Rating of including engineering skills (Q1 to Q12) 
Table 2: Importance of abilities in the quality engineering training program

\begin{tabular}{ll}
\hline Q1 & The ability to diagnose mechanical faults \\
Q2 & $\begin{array}{l}\text { The ability to diagnose faults electromechanical } \\
\text { The ability to diagnose mechanical failure resulting from a } \\
\text { mismatch specifications }\end{array}$ \\
Q4 & $\begin{array}{l}\text { The ability to identify the immediate needs for unscheduled } \\
\text { tasks }\end{array}$ \\
Q5 & $\begin{array}{l}\text { The ability to determine the times needed to complete the } \\
\text { project }\end{array}$ \\
Q6 & $\begin{array}{l}\text { The ability to overcome obstacles and barriers } \\
\text { The ability to take advantage of the obstacles and }\end{array}$ \\
Q7 & $\begin{array}{l}\text { impediments } \\
\text { The ability to transform obstacles and impediments to } \\
\text { opportunities for success }\end{array}$ \\
\hline
\end{tabular}

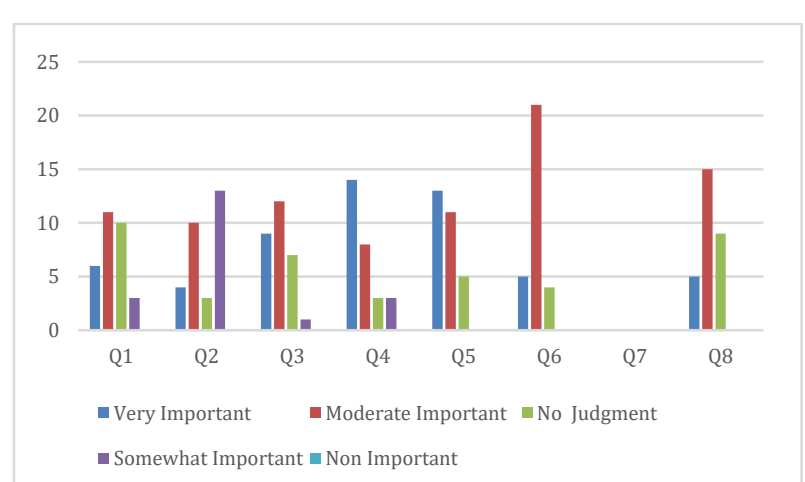

Fig. 4: Rating of including engineering abilities (Q1 to Q12)

Table 3: Yes or NO questions

Q1 Engineering projects training is an urgent need for current UoH Engineering projects

2 UoH engineering projects lack of communication between engineering branches among the new hired engineers UoH engineering projects lack of communication between

Q3 engineering branches among the management engineers level.

Q4 Current engineering training projects are limited to higher engineering staff

Q5 The current learning content of quality related teaching are limited to the institution research vision and plan

Q6 The current engineering staff is equipped with adequate

Q6 skills to meet the future needs of $\mathrm{UoH}$ engineering projects.

Q7 Most of the current $\mathrm{UoH}$ engineering projects problems are

Q7 due to lake of planning among different branches

Q8 College if engineering visiting is a priority in the future

Q8 training plan for quality engineering training

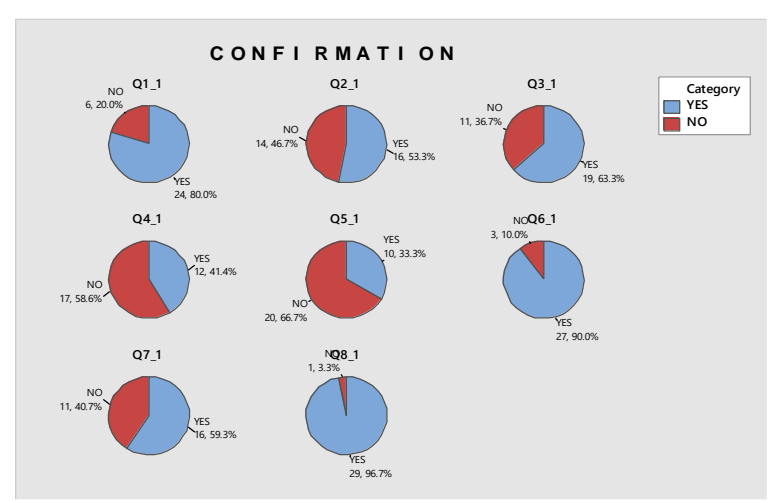

Fig. 5: YES/NO rating

These skills needs to be taught in the time periods as shown in Fig. 6.

\section{Conclusion}

This study emphasize the importance improving the execution of construction project at $\mathrm{UoH}$ through engineering training and discussed the causes of delay among the engineering projects at University of Hail. There are several causes for the delay, which are combined into three areas, namely late executive decisions, communication among teams, and unplanned project expansion. A questionnaire was distributed among different levels of engineers and a table is established to show the questionnaire results.

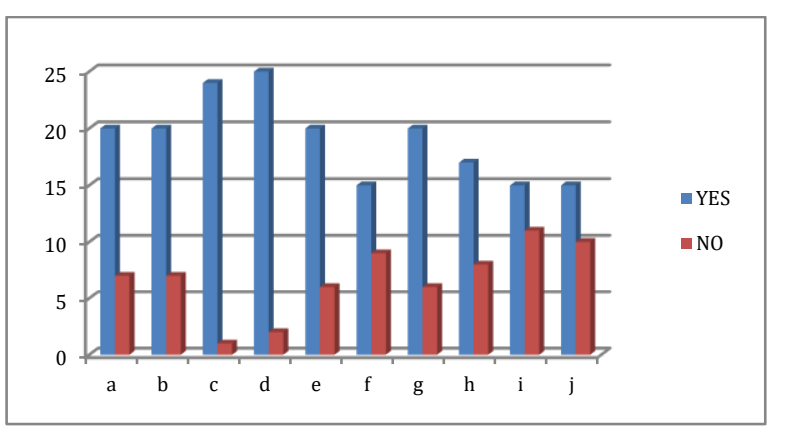

Fig. 6: YES/NO Time interval for proposed courses

Table 4: Rate the level of agreement of the following statement

Q1 UoH current projects have not changed significantly

Q1 throughout the life of the project to-date

Q2 The requirements for this UoH current projects are not welldefined

Q3 The engineering project team has successfully completed projects similar to UoH current projects in the past

Q4 The quality engineering training project makes effective use of integrated engineering teams

Q5 UoH and the local companies should participate in the quality engineering training project

Q6 Significant constraints are placed on the quality attributes

Q7 (e.g. reliability, Scalability, security, supportability, etc.) of

Q7 the engineering training project

Q8 UoH current projects technically challenging

Q9 Sufficient resources (e.g. people, funding) are available to Q9 support the project

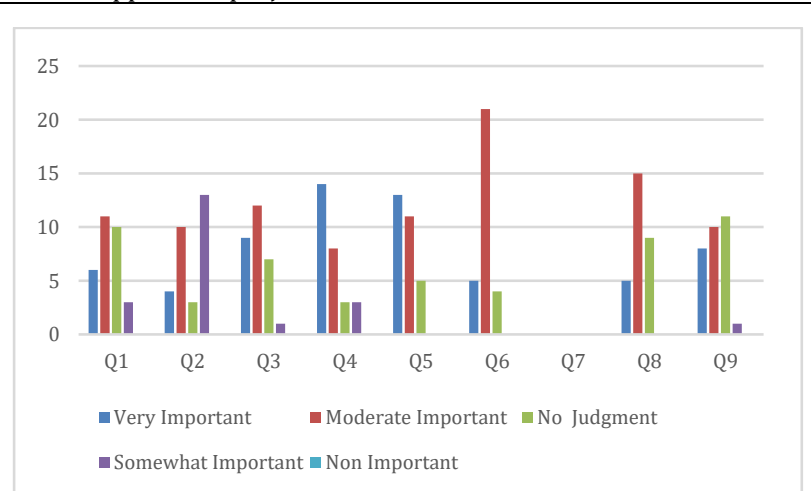

Fig. 7: Rating of importance (Q1 to Q9)

This research illustrates that engineering training is crucial to avoid poor quality and work delay. The arguments addressed in this study aimed at minimizing, if not eliminating, all constraints that may lead to undesirable results. The owner of any construction project at the University of Hail shall set the criteria required for the engineering training to be conducted and assign weight for each criterion based on its importance from the owner's point of view.

The study proposed an innovative training content for creating the strategies and rules for 
quality in the cooperation or institution, in addition to innovating solutions to the measurement problems throughout all the stages of project execution. The findings of the paper suggest that the contractor and owner/client related factors are the most critical factors that cause to delay the construction projects in $\mathrm{UoH}$.

A questionnaire was conducted to assess urgent training needs that influence the performance and progress of the engineering projects at University of Hail.

Further research is recommended to develop a queuing model that should restrict or eliminate causes of delay in the construction project by managing project resources through Lean Manufacturing and Six Sigma strategies.

\section{Acknowledgement}

This work is funded by Deanship of Academic Research by a grant for project number (E-27-ME)

\section{References}

Adrian JJ (1987). Construction productivity improvement. Elsevier Science Publishing Co, New York, USA.

Al-Hammad AM and Assaf S (1996). Assessment of work performance of maintenance contractors in Saudi Arabia. Journal of Management in Engineering, 12(2): 44-49.

Al-Yousefi AS, Al-Khuwaiter A, Al-Oshaish S, and Shublaq E (1999). Value engineering in Saudi Arabia: Overview and applications in public and private sectors. In the Save International Conference, USA: 9-17.

IPA (2011). Institute of Public Administration website. Available online at: https://www.ipa.ie/

Mojahed S and Aghazadeh F (2008). Major factors influencing productivity of water and wastewater treatment plant construction: Evidence from the deep south USA International Journal of Project Management, 26(2): 195-202.

SCE (2012). Saudi Council of Engineer. Available online at: http://www.saudieng.org/sites/searabic/Pages/default_01.as px 